\title{
Successful Ombitasvir/Paritaprevir/Ritonavir Plus Ribavirin Retreatment for a Chronic Hepatitis C Genotype 2a Patient Who Relapsed after Sofosbuvir Plus Ribavirin Treatment
}

\author{
Toru Ishikawa, Michitaka Imai, Takashi Owaki, Hiroki Sato, Yujiro Nozawa, Tomoe Sano, \\ Akito Iwanaga, Keiichi Seki, Terasu Honma and Toshiaki Yoshida
}

\begin{abstract}
:
The optimum retreatment strategy for chronic hepatitis $\mathrm{C}$ virus $(\mathrm{HCV})$ patients who failed directly-acting antiviral agents (DAA)-based therapy is unknown. We herein report the outcomes of an HCV genotype (GT) 2a-infected patient with virologic failure following treatment with sofosbuvir plus ribavirin (SOF+RBV) who was successfully retreated with ombitasvir/paritaprevir/ritonavir plus ribavirin (OBV/PTV/r+RBV).
\end{abstract}

Key words: $\mathrm{HCV}$ genotype 2a, retreatment, sofosbuvir plus ribavirin, ombitasvir/paritaprevir/ritonavir plus ribavirin

(Intern Med 57: 2843-2845, 2018)

(DOI: 10.2169/internalmedicine.0621-17)

\section{Introduction}

Recently, interferon (IFN)-free DAA-based combination therapy has become mainstream in the treatment of chronic hepatitis $\mathrm{C}(\mathrm{CHC})(1)$. Thus, the effectiveness and safety of several DAA regimens have been reported in detail since such agents become available.

However, DAA therapies are unfortunately unsuccessful in some cases. Few clinical experiences have been reported regarding retreatment options for patients who fail their first DAA regimen (2). Therefore, selecting retreatment options is an important matter to consider for the future.

We herein report the successful outcomes of retreatment with $\mathrm{OBV} / \mathrm{PTV} / \mathrm{r}+\mathrm{RBV}$ in an HCV GT2a-infected patient with virologic failure following treatment with sofosbuvir plus ribavirin $(\mathrm{SOF}+\mathrm{RBV})$.

\section{Case Report}

A 75-year-old woman with a history of small intestine bleeding had been diagnosed with HCV GT2a infection at 70 years of age in 2012. Her single-nucleotide polymorphism (SNP) of the interleukin 28B (IL28) polymorphism was TT genotype (rs8099917). A histological diagnosis of chronic hepatitis $\mathrm{C}$ was established, with Grade 2 inflammatory activity (grading), and Grade 3 fibrosis (staging). She was treated with peginterferon plus ribavirin (PEGIFN+ RBV) in 2013 after partial splenic arterial embolization (PSE) for thrombocytopenia. However, she was a nonresponder to PEGIFN+RBV.

In July 2016, she began treatment with an all-oral regimen of sofosbuvir (SOF) at $400 \mathrm{mg}$ daily and ribavirin (RBV) at $600 \mathrm{mg}$ daily. At the time of starting the treatment, her height and weight were $155.2 \mathrm{~cm}$ and $48.35 \mathrm{~kg}$, respectively. Her viral load was $4.9 \mathrm{Log} \mathrm{IU} / \mathrm{mL}$ at baseline, and it became undetectable at week 4 of treatment, remaining undetectable throughout the 12 weeks of treatment. Treatment adherence was maintained because there were no serious adverse events during the $\mathrm{SOF}+\mathrm{RBV}$ treatment. However, at 4 weeks after treatment had ended, the viral load increased to $5.9 \mathrm{Log} \mathrm{IU} / \mathrm{mL}$, indicating relapse.

At that time, the newest and particularly potent DAA regimen, glecaprevir (nonstructural protein 3/4A protease inhibitor) and pibrentasvir (nonstructural protein $5 \mathrm{~A}$ inhibitor), had not yet been approved in Japan. Therefore, we chose OBV/PTV/r at 25/150/100 mg daily and RBV at $600 \mathrm{mg}$ daily for retreatment of this patient in January 2017. This 


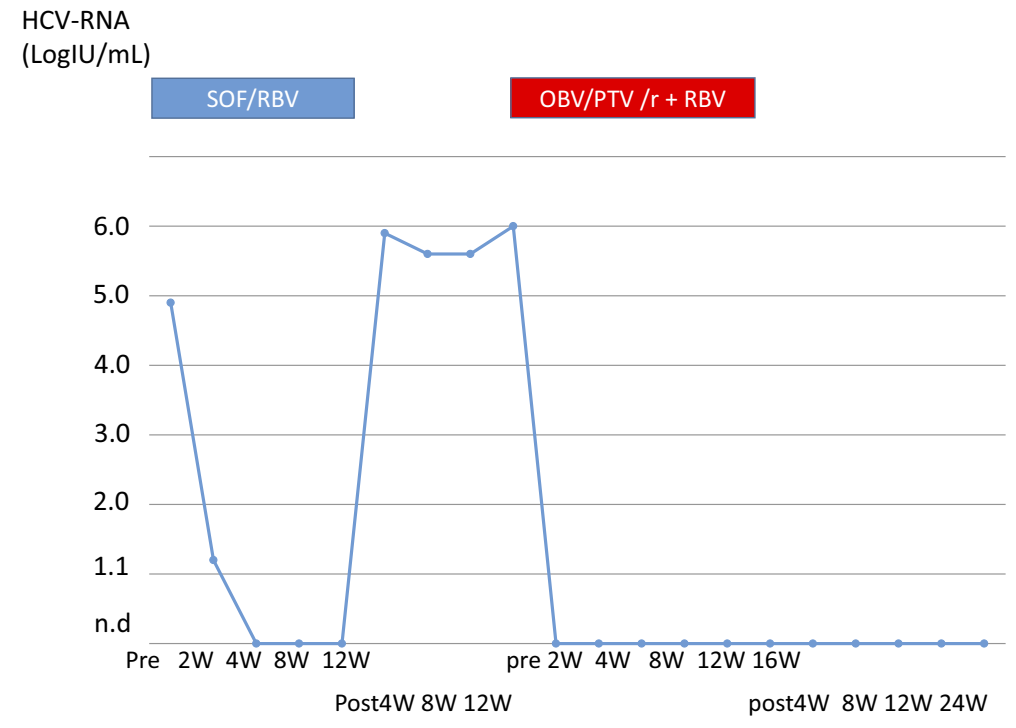

Figure. The clinical course of the patient. SOF+RBV: sofosbuvir plus ribavirin, OBV/PTV/r+RBV: ombitasvir/paritaprevir/ritonavir plus ribavirin, n.d: not detected, Pre: pretreatment

was due to the fact that the $\mathrm{OBV} / \mathrm{PTV} / \mathrm{r}+\mathrm{RBV}$ regimen showed high sustained virologic response (SVR) rates in GT 2a CHC patients in Japanese phase 3 studies. After 2 weeks of $\mathrm{OBV} / \mathrm{PTV} / \mathrm{r}+\mathrm{RBV}$ treatment, the viral load decreased from $5.9 \mathrm{Log} \mathrm{IU} / \mathrm{mL}$ to undetectable, ultimately achieving SVR24 (Figure). Furthermore, there were no serious adverse effects of the OBV/PTV/r+RBV treatment.

\section{Discussion}

In Japan, an estimated 1.4-1.6 million people are infected with $\operatorname{HCV}(3,4)$. An estimated $67 \%$ of HCV-infected patients in Japan are infected with HCV GT1b, while approximately $22 \%$ are infected with HCV GT2a and $10 \%$ with HCV GT2b (5). With the introduction of all-oral, IFN-free DAAs, new treatment options are becoming available for patients with HCV GT2 infection. Combination therapy of the nucleic acid type NS5B polymerase inhibitor $\mathrm{SOF}+\mathrm{RBV}$ is recommended according to the treatment guidelines of the Japanese Society of Hepatology as a first-line therapy for treatment-naïve patients with HCV GT2 infections, except for those severe renal dysfunction or renal failure needing dialysis (6).

In accordance with these guidelines, we have introduced SOF+RBV therapy in several HCV GT2 patients; unfortunately, however, this approach failed in the present patient. A large, multicenter study of SOF+RBV for patients with HCV GT2 infections showed that non-cirrhosis was independently associated with SVR12 (7). Therefore, this patient might have failed to achieve SVR with SOF+RBV due to progression of hepatic fibrosis. Combination therapy with the NS5A inhibitor ombitasvir (OBV) and the NS3/4A protease inhibitor paritaprevir (PTV) has shown potent antiviral activity against multiple HCV types, including 1a, 1b, 2a, $2 \mathrm{~b}, 3 \mathrm{a}, 4 \mathrm{a}$, and $6 \mathrm{a}$, in vitro $(8,9)$.

In a clinical trial conducted in Japan, the SVR12 rates were consistently higher in patients with HCV GT2a infection compared with HCV GT2b infection. In the week 16 treatment arm, the SVR rates for HCV GT2a and GT2b were $93.9 \%$ and $85.7 \%$, respectively, in treatment-naïve patients and $93.8 \%$ and $56.3 \%$, respectively, in treatmentexperienced patients (10). The factors that were identified as associated with higher odds of SVR12 based on a stepwise logistic regression analysis were HCV GT2a infection and no treatment experience (10).

Based on these findings, even if the treatment failed with $\mathrm{SOF}+\mathrm{RBV}$ combination therapy, there may be a possibility of retreatment with $\mathrm{OBV} / \mathrm{PTV} / \mathrm{r}+\mathrm{RBV}$ combination therapy with different mechanism of action being successful. In addition, since the present patient had a GT2a, SVR was achieved by introducing retreatment with $\mathrm{OBV} / \mathrm{PTV} / \mathrm{r}+\mathrm{RBV}$ combination therapy.

Recently, the safety and efficacy of combination therapy of glecaprevir (nonstructural protein 3/4A protease inhibitor) and pibrentasvir (nonstructural protein $5 \mathrm{~A}$ inhibitor) $(\mathrm{G} / \mathrm{P})$, which is a RBV free DAA regimen, was evaluated in Japanese patients infected with HCV GT2 (11). Research is needed to clarify the underlying causes of DAA-based treatment failure and to identify the best salvage regimens for patients who have failed certain drug combinations.

In summary, this case study shows that HCV GT2a infected patients experiencing virologic failure with $\mathrm{SOF}+$ RBV therapy can be re-treated with other therapies, such as OBV/PTV/r+RBV regimens, containing components with a different mechanism of action from the initial treatment.

The authors state that they have no Conflict of Interest (COI).

\section{References}

1. Sarrazin C, Hézode C, Zeuzem S, Pawlotsky JM. Antiviral strategies in hepatitis C virus infection. J Hepatol 56: S88-S100, 2012. 
2. Premoli C, Aghemo A. Directly acting antivirals against hepatitis $C$ virus: mechanisms of action and impact of resistant associated variants. Minerva Gastroenterol Dietol 62: 76-87, 2016.

3. Messina JP, Humphreys I, Flaxman A, et al. Global distribution and prevalence of hepatitis $\mathrm{C}$ virus genotypes. Hepatology 61: 77$87,2015$.

4. Gower E, Estes C, Blach S, Razavi-Shearer K, Razavi H. Global epidemiology and genotype distribution of the hepatitis $\mathrm{C}$ virus infection. J Hepatol 61: S45-S57, 2014.

5. Matsuo J, Mizui M, Okita H, et al. Follow up of the 987 blood donors found with hepatitis $\mathrm{C}$ virus infection over 9-18 years. Hepatol Res 42: 637-647, 2012.

6. Japan Society of Hepatology. JSH guidelines for the management of hepatitis $\mathrm{C}$ virus infection, version 5.4 (in Japanese) [Internet]. [cited 2017 Apr. 30]. Available from: http://www.jsh.or.jp/

7. Ogawa E, Furusyo N, Nomura H, et al. Effectiveness and safety of sofosbuvir plus ribavirin for HCV genotype 2 patients 65 and over with or without cirrhosis. Antiviral Res 136: 37-44, 2016.

8. Krishnan P, Beyer J, Mistry N, et al. In vitro and in vivo antiviral activity and resistance profile of ombitasvir, an inhibitor of hepatitis C virus NS5A. Antimicrob Agents Chemother 59: 979-987, 2015.

9. Pilot-Matias T, Tripathi R, Cohen D, et al. In vitro and in vivo antiviral activity and resistance profile of the hepatitis $\mathrm{C}$ virus NS3/4 A protease inhibitor ABT-450. Antimicrob Agents Chemother 59: 988-997, 2015.

10. Sato K, Chayama K, Alves K, et al. Randomized phase 3 trial of ombitasvir/paritaprevir/ritonavir and ribavirin for hepatitis $\mathrm{C}$ virus genotype 2-infected Japanese patients. Adv Ther 34: 1449-1465, 2017.

11. Toyoda H, Chayama K, Suzuki F, et al. Efficacy and safety of glecaprevir/pibrentasvir in Japanese patients with chronic genotype 2 hepatitis C virus infection. Hepatolgy 67: 505-513, 2018.

The Internal Medicine is an Open Access article distributed under the Creative Commons Attribution-NonCommercial-NoDerivatives 4.0 International License. To view the details of this license, please visit (https://creativecommons.org/licenses/ by-nc-nd/4.0/).

(C) 2018 The Japanese Society of Internal Medicine

Intern Med 57: 2843-2845, 2018 